\title{
Ring Expansion to 8-Membered Silacycles via Formal Cross-Dimerization of 5- Membered Palladacycles with Silacyclobutanes
}

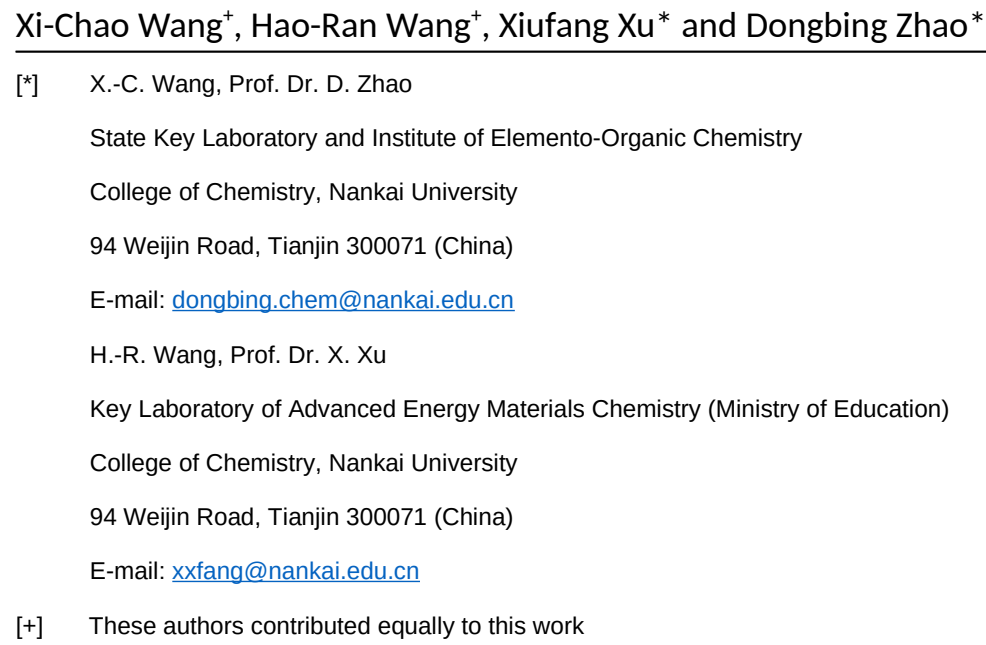

\begin{abstract}
Investigations of the sila-8-membered ring fused biaryls are of important significance for the discovery of new drug lead compounds. However, such compounds are still unknown due to the synthetic challenge. Herein we describe the chemo- and regio-selective cross-dimerization of 5-membered palladacycles with silacyclobutanes enabled by $\mathrm{Pd}$-catalytic conditions, which constitutes an expedient ring expansion route to the sila-8-membered ring fused biaryl skeletons.
\end{abstract}

Silasubstitution of biologically active molecules has attracted increased interest in drug discovery. ${ }^{[1]}$ Because it proved that silicon incorporation often resulted in modifying physiological and biological activities, molecular size and shape, lipophilicity as well as toxicology. The eight-membered ring bridged biaryl motifs $\mathbf{A}$ are prevalent in a broad variety of natural products (Scheme 1a). ${ }^{[2]}$ Thus, investigations of the sila-8-membered ring fused biaryls $\mathbf{B}$ are of important significance for the discovery of new drug lead compounds. However, such compounds are still unknown due to the synthetic challenge on incorporation of a silicon atom at the ring junction of the biaryl frameworks A.

A retrosynthetic analysis shows that the cycloaddition of strained silacycle with $\pi$ bonds, which is the most well-known ring expansion strategy, ${ }^{[3,4]}$ is incapable of delivering such sila-8-membered ring fused biaryl skeletons. Recently, a few examples on ring expansion through transition metal-catalyzed formal cross-dimerization of strained (benzo)-silacyclobutanes and 3- or 4-membered cyclic ketones with 100\% atom economy developed by Murakami and our group have dramatically expanded chemists' toolbox, ${ }^{[5]}$ enabling rapid construction of specific 7 or 8-membered sila-cyclic ketones (Scheme 1b), which often require tedious multistep synthesis. Inspired by this attractive and modular strategy for rapid delivery of larger ring systems, we wonder if such sila-8-membered ring fused biaryl skeletons can also be efficiently approached by transition metal catalyzed cross-dimerization of strained (benzo)-silacyclobutanes and biphenylenes. Notably, biphenylenes have been widely utilized as biaryl-synthons in a variety of 
transformations such as homo-coupling and cycloaddition with alkynes or alkenes owing to their high ring strain energy, which would facilitate the $C-C$ bond cleavage via metal insertion to form the corresponding dibenzo-metallacyclopentadienes. ${ }^{[6]}$ However, until now transition metal-catalyzed cross-dimerization of biphenylenes with strained ring has not been explored. To realize this transformation, the reactivities of these two strained rings need to be highly differentiated and the well-documented preferential homodimerization of strained rings by choice of the proper catalytic system. Herein, we achieved the formal cross-dimerization of 5-membered palladacycles generated from $\mathrm{C}-$ $\mathrm{C}$ bond cleavage of biphenylenes or $\mathrm{C}-\mathrm{H}$ bond activation of 2-iodobiphenyls and 1-(tertbutyl)-2-iodobenzenes with silacyclobutanes by employing $\mathrm{Pd}(0)$-catalytic system, enabling to directly access the structurally diverse sila-8-membered ring fused biaryl skeletons and benzoannulenes (Scheme 1c).

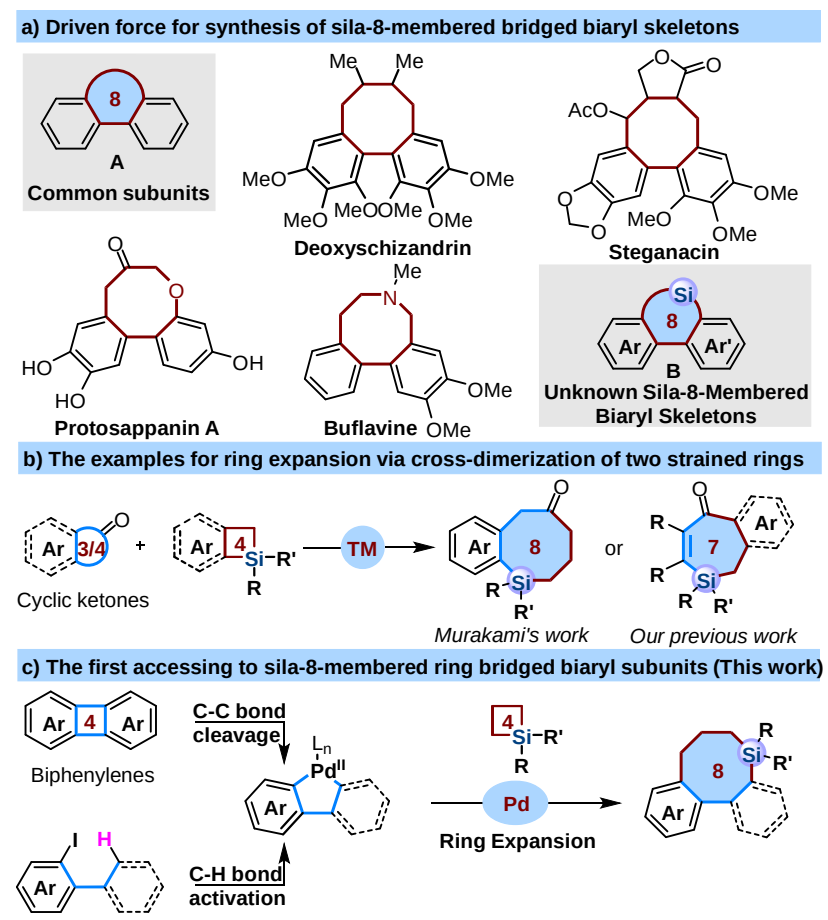

Scheme 1. Driven force and our study for synthesis of sila-8-membered ring fused biaryls.

In preliminary experiments, biphenylene $\mathbf{1 a}$ and silacyclobutane $\mathbf{2 a}$ was subjected to Pd-catalytic conditions to try to access sila-8-membered ring fused biphenyl 3aa. We found that the cross-dimerization of biphenylene $\mathbf{1 a}$ and silacyclobutane $\mathbf{2 a}$ smoothly occurred to yield the desired product $3 \mathbf{3 a}$ in $98 \%$ yield with $\mathrm{Pd}(\mathrm{dba})_{2}(1 \mathrm{~mol} \%)$ and 2dicyclohexylphosphino-2'-(N,N-dimethylamino)biphenyl (DavePhos,10 mol\%) in toluene $(1 \mathrm{~mL})$ at $100{ }^{\circ} \mathrm{C}$ for $24 \mathrm{~h}$ (Equation $\mathrm{A}$ ). Considering the higher strain energy of biphenylene $1 \mathbf{a}$, we rationalized that the reaction was triggered by the oxidative addition of $\mathrm{Pd}^{0}$ species to $\mathrm{C}-\mathrm{C}$ bond of biphenylene to form the dibenzopalladacyclopentadiene. Following the proposal, we synthesized the corresponding palladacycle $\mathbf{P d - 1 a}$ and found that the reaction of palladacycle $\mathbf{P d}-\mathbf{1} \mathbf{a}$ and silacyclobutane $\mathbf{2 a}$ proceed smoothly to 
deliver the product $3 \mathrm{a}$ in toluene at $100^{\circ} \mathrm{C}$ for $24 \mathrm{~h}$ (Equation B), which clearly proved our speculation. Besides the way to dibenzopalladacyclopentadienes via $\mathrm{C}-\mathrm{C}$ activation of biphenylenes, $\mathrm{C}-\mathrm{H}$ activation of 2-iodobiphenyls is also a reliable alternative to achieve the same palladacycle (Equation C). ${ }^{[7]}$ Thus, we assumed that 2-iodobiphenyls might also react with silacyclobutane $\mathbf{2 a}$ to approach the silacycle $\mathbf{3 a a}{ }^{[8]}$ Fortunately, after extensive survey of the reaction parameters (for more details, see $\mathrm{SI}$ ), the ring expansion product 3aa was formed in $86 \%$ yield by treatment of 2-iodobiphenyl $4 \mathrm{a}$ with silacyclobutane 2a, $\mathrm{Pd}(\mathrm{dba})_{2}$ (5 mol\%), DavePhos (10 mol\%) and KOAc (2.0 equiv) in DMSO at $110{ }^{\circ} \mathrm{C}$ for $12 \mathrm{~h}$ (Equation $\mathrm{D}$ ).

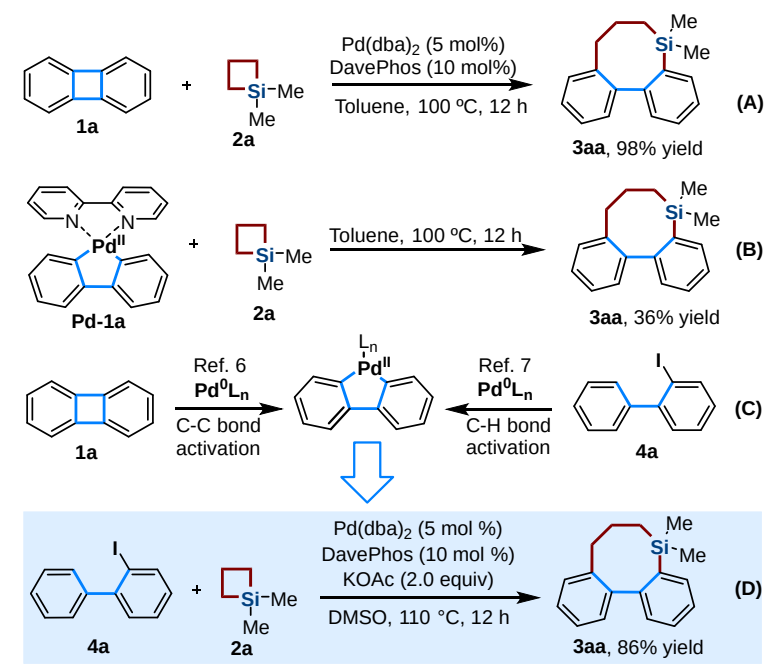

Considering the wider accessibility and functional group compatibility of 2iodobiphenyls, we extended the substrate scope of this $\mathrm{Pd}$-catalytic ring expansion protocol by treatment of diverse 2-iodobiphenyls $\mathbf{4}$ and silacyclobutanes $\mathbf{2}$ under the optimized conditions, affording the unkown 8-membered sila-tricyclic biaryl skeletons (Table 1). First, the substituent effect of the silacyclobutanes on the silicon atom has been investigated. 1,1-Dialkylsilacyclobutanes are well tolerated $(\mathbf{2} \mathbf{b}-\mathbf{c})$, giving the desired products $\mathbf{3} \mathbf{a b}-\mathbf{a c}$ in high yields, albeit the reaction of $\mathbf{4 a}$ with 1,1diphenylsilacyclobutane $\mathbf{2} \mathbf{d}$ suffers from low yield of $\mathbf{3 a d}$ due to the increased steric hindrance of $\mathbf{2 d}$. Furthermore, we found that diverse 1-methyl-substituted silacyclobutanes bearing phenyl, benzyl and sterically hindered $t$-butyl group at the Si center $(\mathbf{2} \mathbf{e}-\mathbf{g})$ also smoothly underwent this reaction in uniformly high yields. Then, the compatibility of the 2-iodobiphenyls under the optimized condition was also examined. It is worthy to note that diverse 2-iodo-3,5-disubstituted-1,1'-biphenyls (4b-e), which have two possible reactive sites for $\mathrm{C}-\mathrm{H}$ activation step, only resulted in single isomer (3ba-ea), indicating that the cyclometalation occurred at the less crowded $\mathrm{C}-\mathrm{H}$ bond position. Additionally, this ring expansion also allows access to structurally diverse sila-8membered ring fused biaryl skeletons bearing a variety of important functional groups such as $\mathrm{F}, \mathrm{Cl}, \mathrm{CF}_{3}, \mathrm{OCF}_{3}$ and $\mathrm{OMe}$ (3ga-ka), which are capable of undergoing further downstream transformations. Likewise, we proved that multisubstituted o-iodobiaryl $4 \mathbf{4}$ \& 
$4 \mathrm{~m}$ were also eligible substrates for this ring expansion reaction to assemble the corresponding 8-membered sila-tricyclic biaryl substructures 3la-ma in good yields.

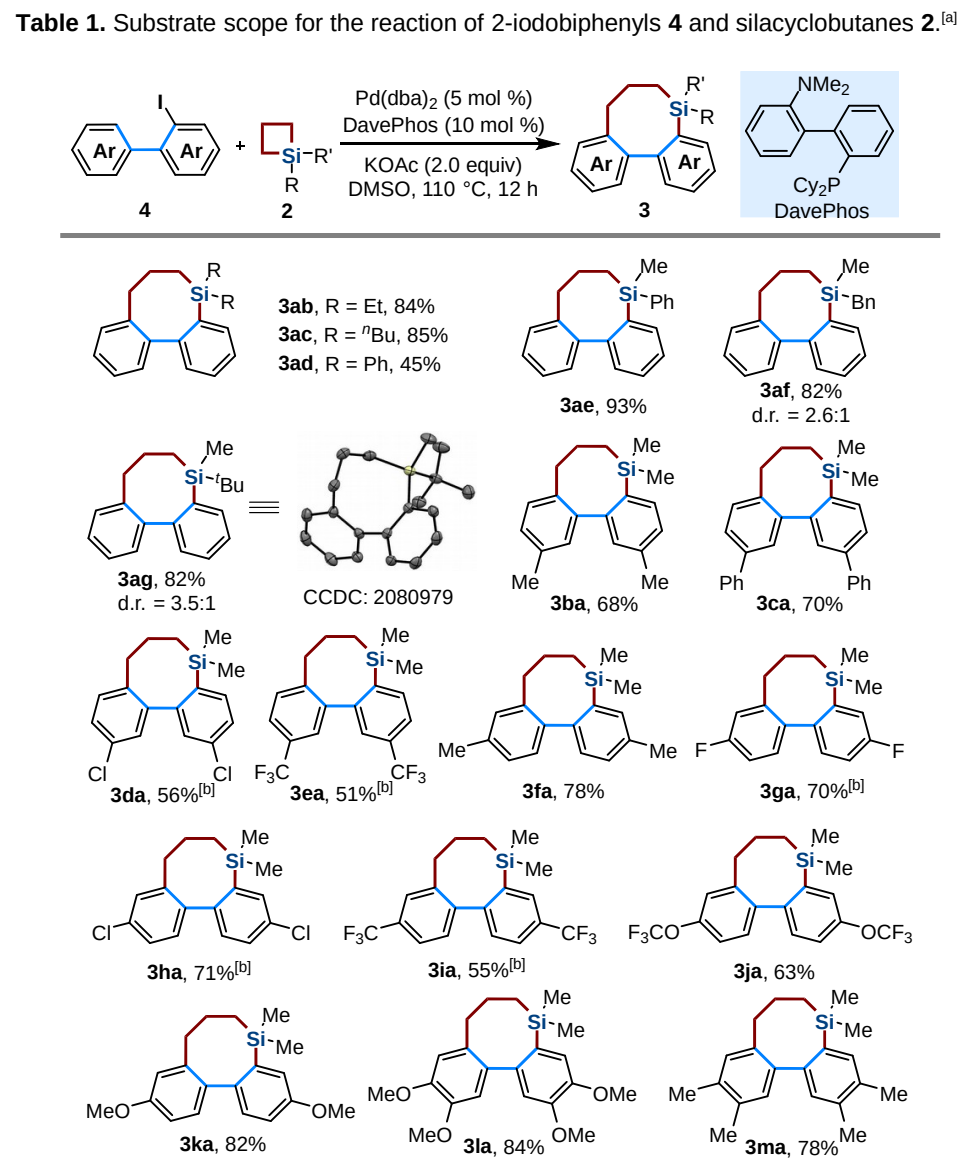

\footnotetext{
[a] In a $\mathrm{N}_{2}$-filled glove box, treatment of 2-iodobiphenyls 4 (0.2 mmol) and silacyclobutanes $2(0.4 \mathrm{mmol})$ in the presence of $\mathrm{Pd}(\mathrm{dba})_{2}(0.01 \mathrm{mmol})$, DavePhos $(0.02 \mathrm{mmol}), \mathrm{KOAC}(0.4 \mathrm{mmol})$ in DMSO $(1.0 \mathrm{~mL})$ at $110{ }^{\circ} \mathrm{C}$ for $12 \mathrm{~h}$. Yields are given for the isolated product. [b] These reactions were conducted by use of $\mathrm{Pd}(\mathrm{dba})_{2}(10 \mathrm{~mol} \%)$ and DavePhos $(20 \mathrm{~mol} \%)$ at $130{ }^{\circ} \mathrm{C}$ for $12 \mathrm{~h}$.
}

Encouraged by the success of these results, we further proceeded to examine the reaction with 1-(tert-butyl)-2-iodobenzene $5 \mathrm{a}$ and silacyclobutane $\mathbf{3 a}$ involving $\mathrm{C}\left(s p^{3}\right)-\mathrm{H}$ activation under the optimized condition. Unfortunately, only trace amounts of the desired product $6 \mathbf{a}$ were provided. After an extensive screening, we found that the reaction occurred smoothly in $77 \%$ yield in the presence of $\mathrm{Pd}(\mathrm{OAc})_{2}(10 \mathrm{~mol} \%), \mathrm{P}(\mathrm{o}-\mathrm{Tol})_{3}(20 \mathrm{~mol}$ $\%$ ) and $\mathrm{Cs}(\mathrm{OAc})_{2}\left(2.0\right.$ equiv) in DMSO at $110^{\circ} \mathrm{C}$ for $24 \mathrm{~h}$ (Scheme 2). The NMR spectra confirmed that only single isomer $\mathbf{6 a}$ was obtained in the reaction. It indicates that the reductive elimination step in this reaction is highly regioselective. 


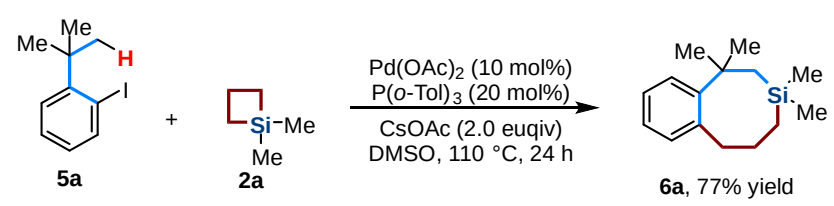

Scheme 2. Regioselective synthesis of 8-membered silacycles via $\mathrm{C}\left(s p^{3}\right)-\mathrm{H}$ bond activation/ $\mathrm{C}\left(s p^{3}\right)-\mathrm{Si}$ bond cleavage

Next, computational studies were carried out to probe the reaction pathway by taking the reaction of $1 \mathbf{a}$ and $\mathbf{2 a}$ as the example and tris(2-methoxyphenyl)phosphine as the ligand. As described above, the key mechanistic question is the competition between the $\mathrm{C}-\mathrm{C}$ bond cleavage of biphenylenes and $\mathrm{C}-\mathrm{Si}$ bond cleavage of silacyclobutanes. The computed energy profiles indicate that the pathway involving the $\mathrm{C}-\mathrm{C}$ bond cleavage of biphenylene $1 \mathrm{a}$ at the beginning of the reaction is more energetically favorable, which is consistent with the aforementioned stoichiometric experiments. The overall activation energy of this pathway is $29.6 \mathrm{kcal} / \mathrm{mol}$ (Scheme 3, from 1a to a-TS1), which is much lower than that of pathway initiated by the $\mathrm{C}-\mathrm{Si}$ bond cleavage of silacyclobutane $\mathbf{2 a}$ (43.8 $\mathrm{kcal} / \mathrm{mol}$, Figure SI from $\mathbf{2 a}$ to $\mathbf{b}$-TS2). Thus, as show in Scheme 3, at first, with the approaching of $\mathrm{PdL}_{2}$ to biphenylene 1a, the rupture of $\mathrm{C} 1-\mathrm{C} 4$ bond takes place via transition state a-TS1 to afford a 5-membered palladacycle $\mathbf{a}-\mathbf{A}$, in which $\mathrm{Pd}-\mathrm{C} 1$ and $\mathrm{Pd}-$ $\mathrm{C} 4$ bond are formed. Before the intermediate $\mathbf{a}-\mathbf{A}$ and silacyclobutane $\mathbf{2 a}$ are complexed, two ligands are released from a-A. Then the rupture of $\mathrm{Si}-\mathrm{C} 5$ bond and the simultaneous formation of $\mathrm{Pd}-\mathrm{Si}$ and $\mathrm{Pd}-\mathrm{C} 5$ bonds occur via the transition state a-TS2 to generate a $\mathrm{Pd}(\mathrm{IV})$ species B. Next, a ligand is coordinated to the metal center $\mathrm{Pd}(\mathrm{IV})$ to afford the intermediate $\mathbf{a - B}$. Subsequently, formation of the $\mathrm{C} 1-\mathrm{Si}$ bond together with the rupture of the $\mathrm{Pd}-\mathrm{C} 1$ and $\mathrm{Pd}-\mathrm{Si}$ bonds occur in a-B via transition state $\mathbf{a}-\mathrm{TS} 3$, to afford a ninemembered palladacycle $\mathbf{a}-\mathbf{C}$. Then, the cyclic $\mathbf{a}-\mathbf{C}$ can go through reductive elimination via transition state a-TS4 to form the product 3aa.

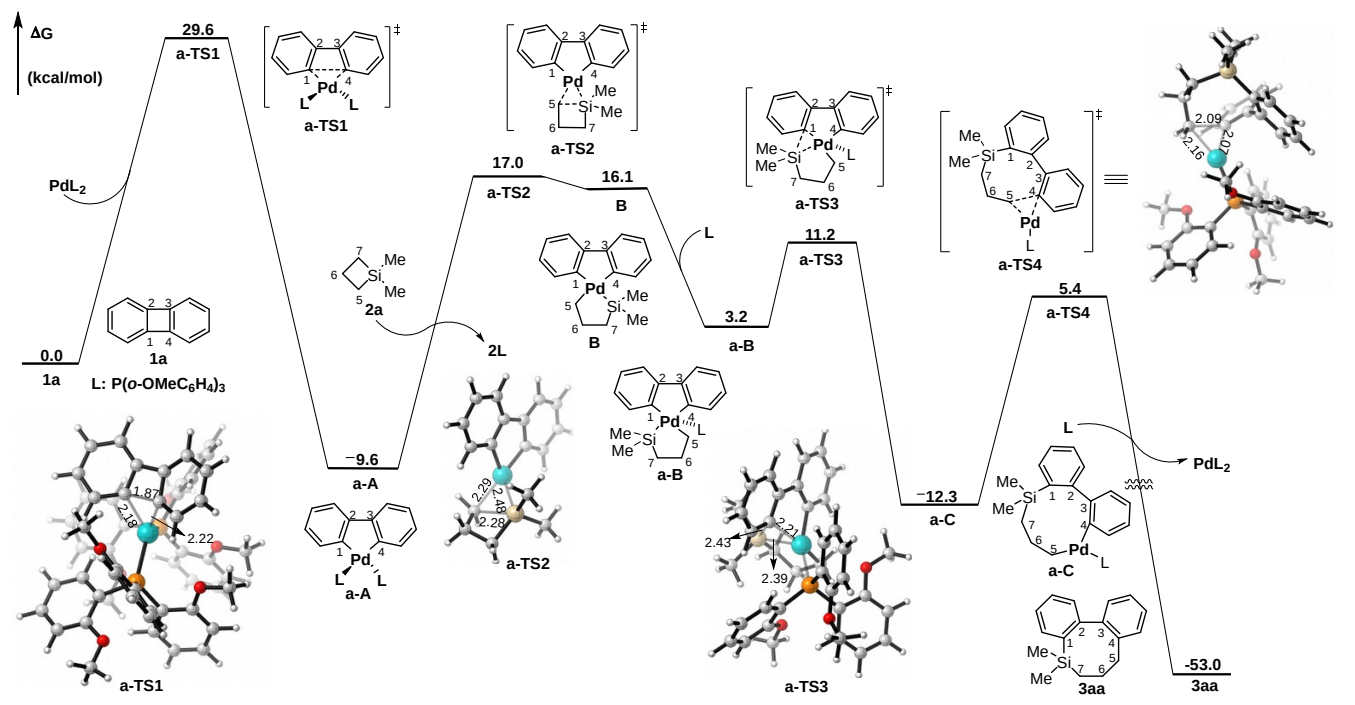

Scheme 3. The computed energy profiles for the Pd-catalyzed formal cross-dimerization of biphenylene 1a with silacyclobutane $\mathbf{2 a}$. 
In summary, we have developed the formal cross-dimerization of biphenylenes and their surrogates with silacyclobutanes by employing $\mathrm{Pd}(0)$-catalytic systems. This facile ring expansion approach constitutes the first method for the modular and robust synthesis of the structurally diverse 8-membered sila-tricyclic biaryl skeletons. The choice of proper ligand and metal catalyst was critical to differentiate the reactivity of the two strained rings, inhibit the competive elementary step and facilitate the regioselective reductive elimination during the reaction. The computational studies indicate that the reaction of biphenylenes with silacyclobutanes undergoes a $\mathrm{Pd}^{\text {o/l/V }}$ cycle, initiated by oxidative $\mathrm{C}-\mathrm{C}$ bond cleavage of biphenylenes.

\section{Acknowledgements}

We are grateful for the financial support from the National Natural Science Foundation of China (21871146, 21873051, 22071114, 22022103), the National Key Research and Development Program of China (2019YFA0210500), the Natural Science Foundation of Tianjin (18JCYBJC20400), the Fundamental Research Funds for the Central Universities and Nankai University.

Keywords: silacycle $\bullet$ ring expansion $\bullet \mathrm{C}-\mathrm{Si}$ bond cleavage $\bullet \mathrm{C}-\mathrm{H}$ bond activation $\bullet$ palladium catalysis

[1] a) W. Bains, R. Tacke, Curr. Opin. Drug Discovery Dev. 2003, 6, 526-543; b) G. A. Showell, J. S. Mills, Drug Discovery Today 2003, 8, 551-556; c) P. Englebienne, A. V. Hoonacker, C. V. Herst, Drug Des. Rev. 2005, 2, 467-483; d) N. A. Meanwell, J. Med. Chem. 2011, 54, 2529-2591; e) A. K. Franz, S. O. Wilson, J. Med. Chem. 2013, 56, 388-405; f) R. Ramesh, D. S. Reddy, J. Med. Chem. 2018, 61, 3779-3798.

[2] a) P. Appukkuttan, W. Dehaen, E. Van der. Eycken, Chem. Eur. J. 2007, 13, 6452-6460; b) A. Joncour, A. Décor, J.-M. Liu, M.-E. Tran H. Dau, O. Baudoin, Chem. Eur. J. 2007, 13, 5450-5465; c) J. Liu, X. Zhou, C. Wang, W. Fu, W. Chu, Z. Sun, Chem. Commun. 2016, 52, 5152-5155; d) O. Baudoin, M. Cesario, D. Guénard, F. Guéritte, J. Org. Chem. 2002, 67, 11991207; e) P. Appukkuttan, W. Dehaen, E. Van der Eycken, Org. Lett. 2005, 7, 2723-2726; f) J. Rotzler, H. Gsellinger, A. Bihlmeier, M. Gantenbein, D. Vonlanthen, D. Häussinger, W. Klopper, M. Mayor, Org. Biomol. Chem. 2013, 11, 110-118.

[3] For some reviews, see: a) Q. C. Mu, J. Chen, C. G. Xia, L.W. Xu, Coord. Chem. Rev. 2018, 374, 93-113; b) L. J. Li, Y. B. Zhang, L. Gao, Z. L. Song, Tetrahedron Lett. 2015, 56, 1466-1473; c) K. Hirano, H. Yorimitsu, K. Oshima, Chem. Commun. 2008, 3234-3241.

[4] For some examples, see: a) X.-B. Wang, Z.-J. Zheng, J.-L. Xie, X.-W. Gu, Q.-C. Mu, G.-W. Yin, F. Ye, Z. Xu, L.-W. Xu, Angew. Chem. Int. Ed. 2020, 59, 790-797; b) H. Chen, Y. Chen, X. Tang, S. Liu, R. Wang, T. Hu, Z. Song, Angew. Chem. Int. Ed. 2019, 58, 4695-4699; c) N. Ishida, S. Okumura, T. Kawasaki, M. Murakami, Angew. Chem. Int. Ed. 2018, 57, 11399-11403; d) J. Liu, Y. Zou, W. Fan, J. Mao, G. Chai, P. Li, Z. Qu, Y. Zong, J. Zhang, P. Kraft, Eur. J. Org. Chem. 2016, 976-982; e) J. Liu, Q. Zhang, P. Li, Z. Qu, S. Sun, Y. Ma, D. Su, Y. Zong, J. Zhang, Eur. J. Inorg, Chem. 2014, 3435-3440; f) R. Shintani, K. Moriya, T. Hayashi, Org. Lett. 2012, 14, 2902-2905; g) R. Shintani, K. Moriya, T. Hayashi, J. Am. Chem. Soc. 2011, 133, 16440-16443; h) K. Hirano, H. Yorimitsu, K. Oshima. Org. Lett. 2008, 10, 2199; i) K. Hirano, H. Yorimitsu, K. Oshima, Org. Lett. 2008, 10, 2199-2201; j) K. Hirano, H. Yorimitsu, K. Oshima, J. Am. Chem. Soc. 2007, 129, 6094-6095; k) N. Agenet, J. H. Mirebeau, M. Petit, R. Thouvenot, V. Gandon, M. Malacria, C. Aubert, Organometallics 2007, 26, 819-830; I) K. Hirano, H. Yorimitsu, K. Oshima, Org. Lett. 2006, 8, 483-485.

[5] a) W.-T Zhao, F. Gao, D. Zhao, Angew. Chem. Int. Ed. 2018, 57, 6329-6332; b) W.-T. Zhao, G. Fang, D. Zhao, Synlett 2018, 29, 2595-2600; c) S. Okumura, F. Sun, N. Ishida, M. Murakami, J. Am. Chem. Soc. 2017, 139, 12414-12417; d) N. Ishida, W. 
Ikemoto, M. Murakami, J. Am. Chem. Soc. 2014, 136, 5912-5915; e) S. Saito, T. Yoshizawa, S. Ishigami, R. Yamasaki, Tetrahedron Lett. 2010, 51, 6028-6030.

[6] a) H. Takano, K. S. Kanyiva, T. Shibata, Org. Lett. 2016, 18, 1860-1863; b) T. Schaub, M. Backes, U. Radius, Organometallics 2006, 25, 4196-4206; c) T. Matsuda, H, Kirikae, Organometallics 2011, 30, 3923-3925; d) T. Satoh, W. D. Jones, Organometallics 2001, 20, 2916-2919; e) B. L. Edelbach, R. J. Lachicotte, W. D. Jones, Organometallics 1999, 18, 4040-4049; f) B. L. Edelbach, D. A. Vicic, R. J. Lachicotte, W. D. Jones, Organometallics 1998, 17, 4784-4794; g) B. L. Edelbach, R. J. Lachicotte, W. D. Jones, J. Am. Chem. Soc. 1998, 120, 2843-2853.

[7] a) A. Lu, X. Ji, B. Zhou, Z. Wu, Y. Zhang, Angew. Chem. Int. Ed. 2018, 57, 3233-3237; b) X. Ma, A. Lu, X. Ji, G. Shi, Y. Zhang, Asian J. Org. Chem. 2018, 7, 1403-1410; c) C. Zhu, D. Wang, D. Wang, Y. Zhao, W.-Y. Sun, Z. Shi, Angew. Chem. Int. Ed. 2018, 57, 8848-8853; d) G. Shi, D. Chen, H. Jiang, Y. Zhang, Y. Zhang, Org. Lett. 2016, 18, 2958-2961; e) M. A. Campo, R. C. Larock, J. Org. Chem. 2002, 67, 5616-5620.

[8] During the preparation of the manuscript, Liu reported palladium-catalyzed $(4+4)$ annulation of silacyclobutanes and 2 iodobiarenes, see: M.-H. Zhu, X.-W. Zhang, M. Usman, H. Cong, W.-B. Liu, ACS Catal. 2021, 11, 5703-5708. 